\title{
Enquadramentos da mídia e o processo de aprendizado social: transformações na cultura pública sobre o tema da deficiência de 1960 a 2008
}

\section{Ana Carolina Vimieiro, Rousiley Celi Moreira Maia}

\section{Resumo}

0 objetivo deste trabalho é analisar a cultura pública mediada sobre o tema da deficiência de 1960 a 2008, no Brasil. Tendo como base a análise de 364 notícias publicadas neste período nos veículos Folha de São Paulo, 0 Globo e Veja, o estudo indica uma intensa pluralização em termos de enquadramentos no decorrer das últimas décadas e o fortalecimento de uma perspectiva de direitos que até os anos 80 não tinha visibilidade. 0 s resultados obtidos contestam 0 ceticismo de estudos prévios quanto à mudança dos valores relacionados ao assunto. Nossa análise a longo prazo, ao comparar os enquadramentos da mídia atuais com os de décadas passadas, aponta para um profundo processo de aprendizado social.

\section{Palavras-chave:}

Cultura pública. Enquadramento. Aprendizado social. Deficiência. Inclusão.

Ana Carolina Vimieiro | carolina.vimieiro@gmail.com Mestre em Comunicação Social pela Universidade Federal de Minas Gerais (UFMG)

Rousiley Celi Moreira Maia | rousiley@fafich.ufmg.br Doutora em Ciência Política pela University of Nottingham (Inglaterra). Professora Associada do Programa de Pós-Graduação em Comunicação Social da Universidade Federal de Minas Gerais (UFMG).

\section{Introdução}

Em 2003, a Agência de Notícias dos Direitos da Infância, a Rede ANDI, entidade da sociedade civil, publicou uma pesquisa sobre 0 tema da deficiência feita com material jornalístico publicado no ano de 2002, no Brasil. 0 estudo indicou que o ideal da inclusão - que faz parte do marco legal brasileiro e é defendido pelas Nações Unidas - não estava tão presente na amostra analisada e que era ainda o modelo integrativo - tido como ultrapassado por muitos grupos ligados ao assunto - que permeava, em sua grande maioria, as notícias que falavam sobre deficiência (VIVARTA, 2003).

A ideia de inclusão surgiu no esteio da luta desencadeada pelos movimentos sociais e outras organizações da sociedade civil relacionadas ao tema ao longo das últimas décadas. Em meados dos anos 1980, a noção até então publicamente forte de integração começou a ser problematizada, na medida em que pressupunha um processo de preparação das pessoas com deficiência para que elas pudessem conviver com os demais. A integração pode ser vista, nesse sentido, como 
um processo de "normalização", na medida em que pressupõe a necessidade de preparação das pessoas com deficiência para que elas possam ser inseridas numa sociedade despreparada para conviver com elas (CERIGNONI; RODRIGUES, 2005; CORRER, 2003).

A noção de inclusão questionou a injustiça de tal ideia, já que tal modelo de inserção social se aplicava a apenas aqueles que fossem considerados aptos para conviver nos sistemas sociais gerais. Segundo o movimento inclusivo, 0 modelo da integração induz a uma noção de que se pode escolher quais seres humanos têm direito a estar nas escolas, nos parques de diversão, nos ambientes de trabalho etc. Esses seres humanos seriam apenas os que conseguissem se adaptar ao mundo dos sem deficiência (VIVARTA, 2003). Nesse sentido, a inclusão não é apenas um modelo de inserção social, mas um ideal promovido por diversos movimentos desde então, que propõe uma abertura da sociedade para a diversidade humana.

Cabe destacar que o modelo integrativo, apesar de ser criticado pelos defensores da inclusão como retrógrado, significou, no momento de seu surgimento, uma inovação com relação aos valores sociais até então vigentes. A noção de integração aparece no Brasil em meados da década de 1960 como alternativa à exclusão total e à segregação institucional das pessoas com deficiência. Além disso, existem também alguns críticos da própria noção de inclusão irrestrita, que é vista como "simplista" quando aplicada à realidade concreta. Nesse sentido, as críticas se concentram sobretudo na área da educação, com um intenso debate entre instituições e entidades que defendem a inclusão total dos alunos com deficiência no sistema regular de ensino e outras que fazem apontamentos significativos no que diz respeito aos limites operacionais desse ideal como as tradicionais Associação de Pais e Amigos dos Excepcionais (Apae) e 0 Instituto Pestalozzi. 0 principal argumento daqueles que são contrários a um processo de inclusão irrestrito é de que existem casos extremos e que, ao invés de defender uma noção de inclusão que não está atenta às especificidades de cada pessoa, é preciso promover a inclusão de forma consciente.

Essa discussão também se articula à contraposição ensino especial x ensino inclusivo e as diferentes interpretações sobre a forma de inserção da educação especial no sistema educacional brasileiro. Além disso, essa disputa entre inserção irrestrita das pessoas com deficiência no sistema regular e valorização da permanência do ensino especializado, sobretudo para pessoas com deficiência mental - largamente fornecido pelas Apaes no contexto brasileiro -, também envolve um volume alto de recursos do Estado destinado à educação de pessoas com deficiência (VIVARTA, 2003).

Dessa forma, os achados da pesquisa da Rede ANDI levantam questionamentos sobre a eficácia de todo o esforço empreendido por essas entidades na tentativa de mudança dos valores sociais 
com relação à deficiência. Apesar da aparente popularidade do próprio termo "inclusão" nos últimos anos e da presença constante do assunto deficiência em novelas, jornais e outros programas, 0 estudo da Rede ANDI aponta razões para pessimismo. Será que efetivamente o cenário que se configura poderia ser analisado apenas como ainda predominantemente dominado pelos valores integrativos?

Em nosso trabalho, realizamos um estudo histórico acerca da cultura pública mediada sobre a temática da deficiência para apreendermos em que medida os valores acerca do assunto se modificaram e se realmente é o modelo integrativo que predomina no horizonte de entendimentos sociais. 0 estudo analisou 364 notícias publicadas de 1960 a 2008 nos jornais Folha de São Paulo e O Globo e na revista Veja. Os resultados empíricos da pesquisa a longo prazo nos permitem apresentar um cenário bastante diferenciado e mais complexo. Identificamos um processo de pluralização em termos de enquadramentos desencadeado a partir dos anos 80 e 0 fortalecimento de uma perspectiva de direitos em que muitos valores inclusivos ganham expressão. Esse contraste de resultados se deve ao fato de que dificilmente análises pontuais e de curto alcance conseguem identificar as tendências presentes em padrões culturais de forma mais ampla, o que contribui para um certo ceticismo.

Começaremos 0 artigo esclarecendo melhor alguns pontos conceituais que estruturam a análise empírica. Na sequência, apresentaremos os procedimentos metodológicos adotados e, por fim, analisaremos os resultados encontrados com base no contexto sócio-histórico relacionado ao tema.

\section{Cultura pública, trajetória discursiva mediada e enquadramentos}

Para compreendermos o fenômeno que analisamos

- a cultura pública - é preciso, ainda que

brevemente, explorarmos alguns conceitos, sobretudo a diferenciação existente entre as noções aqui adotadas e outras correlatas. A primeira dessas relações/distinções que precisa ser clareada é aquela entre cultura pública e opinião pública. Neste trabalho, partimos da noção de cultura pública proposta por Peters (2008), que a define como uma gama de símbolos e sentidos que circulam publicamente ou são acessíveis publicamente, relacionados ou endereçados a um público ampliado. Essa cultura, diz Peters (2008), pode se articular de forma discursiva ou expressiva. Para ele, sentidos discursivos são aqueles articulados na linguagem escrita ou falada e que podem ser contestados. Já os expressivos são representados por símbolos não linguísticos, práticas simbólicas ou por usos não 
literais, figurativos e poéticos da linguagem. 0 foco de Peters (2008) em seu trabalho, assim como também é o nosso, são os sentidos discursivos.

Conforme 0 autor afirma, na cultura pública discursiva, ${ }^{1}$ existem muitos elementos que estão circulando de alguma forma entre o público em geral - é aquilo que ele chama de interpretações gerais - e existem aquelas que pertencem de certa forma a uma coletividade, a uma forma específica de vida de um grupo - que ele chama de interpretações coletivas ou autoentendimento coletivo. São identificações culturais, que são comuns em um grupo e que, em algum momento, podem se tornar compartilhadas, aceitas por aqueles que não são daquele grupo. Assim, amplos estoques de conhecimento comum, uma quantidade imensa de informações factuais, normas tácitas, convenções culturais e crenças, assim como identificações históricas, éticas, entendimentos compartilhados sobre os problemas e ações futuras fazem parte da diversidade de interpretações, símbolos e significados contidos no escopo da cultura pública. Dessa forma, a cultura pública é uma espécie de cultura comum ou mesmo senso comum, aqui não entendido em um sentido pejorativo, mas sim como aqueles entendimentos compartilhados de forma mais ou menos ampla pela sociedade ou por uma comunidade específica.
Peters (2008) também relaciona a ideia de cultura pública com a noção de comunicação pública, que diz respeito ao tipo de comunicação livremente acessível, sem restrições formais ou condições especiais para participação - diferentemente daquelas formas de comunicação que são restritas a grupos particulares, protegidas por normas de privacidade ou confidencialidade e limitadas por condições de associação como membro. De acordo com o autor, a comunicação pública é o lugar onde a cultura pública ganha escopo, onde ela é produzida e reproduzida, disseminada e disputada.

Nesse sentido, a diferenciação entre a cultura pública e o que Peters (2008) chama de deliberação pública auxilia na compreensão da diferenciação entre cultura pública e opinião pública. Como um tipo bastante específico de comunicação, diz Peters (2008), a deliberação envolve a parte discursiva da cultura. Porém, nem tudo que é discursivo é necessariamente deliberação. Nesse sentido, ele diz que no material jornalístico existem aqueles formatos que ressaltam a argumentação, como editoriais e artigos de cunho mais opinativo. E aquela parte, mais informacional, que não pode ser considerada como efetivamente deliberação, já que não há argumentos e contraposições sendo acionadas. 
Compreendemos que a ideia de cultura pública se aproxima da de um "pano de fundo cultural" sob o qual uma opinião pública forte se formaria (CHAMBERS, 1996). ${ }^{2}$

Uma segunda distinção que precisa ser explorada, novamente de forma breve, é a que se estabelece entre cultura pública, esfera pública e mídia. Os media de massa constituem o "[...] espaço de exposição, exibição, visibilidade e, ao mesmo tempo, de discurso, discussão e debate [...]." (GOMES, 2008, p. 118) predominante em nossa sociedade. Eles estabelecem uma importante ligação com a esfera pública e também com a cultura pública. Gamson e Modigliani (1989) entendem que o discurso público mediado e a opinião pública são dois sistemas paralelos que interagem. Para eles, mais do que um único discurso público, é mais útil pensar em uma variedade de discursos, que acontecem em diferentes fóruns e que interagem de forma complexa. Assumimos que a relação que se estabelece entre mídia e esfera pública é de pré-estruturação: os meios de comunicação interferem na configuração da esfera pública, mas não a determinam, já que esse não é o único espaço de discussão contemporâneo, nem um espaço exclusivo de debate (MAIA, 2004, 2008; GOMES, 2008). Sendo assim, a esfera pública e a opinião pública se relacionam com a mídia numa relação circular, sendo que nem a esfera pública se resume ao material midiático e nem a cena pública midiática se restringe a debates argumentativos. Portanto, a cultura pública permeia tanto os debates mais deliberativos quanto o conteúdo de entretenimento e mesmo a parte do conteúdo informacional mais factual. Como já apontamos, a cultura pública constitui o pano de fundo para a formação da opinião pública.

Neste sentido, justifica-se o nosso uso da expressão trajetória discursiva mediada. Como grande espaço contemporâneo de visibilidade, é no ambiente midiático que diferentes discursos disputam sentidos; é neste lugar que diversos atores sociais e instituições lutam pela definição e construção da realidade social (GAMSON; MODIGLIANI, 1989). Gamson e Modigliani (1989, p. 3, tradução nossa) explicam o porquê de se olhar para o material midiático quando pensamos em apreender as interpretações que a sociedade tem sobre uma temática:

Se se está interessado em prever os efeitos políticos, eles não são necessariamente 0 mais importante fórum. Mas, se se está interessado na opinião pública, então 0 discurso da mídia domina a ampla cultura de uma temática, tanto refletindo ela quanto contribuindo para a sua criação.

Gamson e Modigliani (1989) utilizam a noção de enquadramento para apreenderem 0 discurso público sobre a temática do poder nuclear nos EUA. A adoção do conceito de enquadramento não só fornece elementos teóricos em consonância com a ideia de cultura pública, como também sustenta a formatação de procedimentos a serem adotados metodologicamente para a identificação das 
interpretações sobre temas públicos presentes no material midiático.

Com relação à noção de enquadramento, existe uma ampla linha de estudos que se dedica ao que vem sendo chamado de framing theory ou frame analysis, sobretudo nos EUA e em alguns países da Europa. As origens do conceito são atribuídas tradicionalmente a Erving Goffman (1974), que teria sido o primeiro autor a sistematizar conceitualmente 0 que seria 0 enquadramento. ${ }^{3}$ Com relação aos enquadramentos da mídia, eles começam a ser estudados empiricamente nos anos 80 com o trabalho de Todd Gitlin (1980) sobre a cobertura jornalística relacionada ao Students for a Democratic Society (SDS), um tradicional movimento estudantil dos EUA da década de 60 . Gamson e Modigliani (1989) e Gamson (1992) também adotam o conceito, o estruturando de forma construtivista e cultural, como padrões de entendimento ancorados no ambiente sóciohistórico. Posteriormente, Entman (1993, 2004) também fornece elementos substanciais para a consolidação desta área como um vasto campo de pesquisas sobre debates de temas públicos que ganham expressão midiática.

Aqui, adotamos o paradigma e o conceito de enquadramento trabalhados por Gamson e Modigliani (1989). Chamamos de paradigma a concepção dos autores de que os enquadramentos midiáticos estão relacionados com as formas de entendimento também presentes na sociedade.
Eles não analisam os frames da mídia como atitudes individuais dos agentes midiáticos, mas sim como esquemas interpretativos substantivos, baseados no ambiente sócio-histórico. Para os autores, os enquadramentos são chaves de sentido que organizam as interpretações coletivas ao associar elementos da realidade social.

Para a análise de nosso material empírico, aplicamos a divisão que os autores propõem entre diferentes "dispositivos simbólicos" que corroboram para a construção do que eles chamam de "pacotes interpretativos". Segundo eles, os "pacotes interpretativos" (interpretative packages) têm uma estrutura interna que abriga uma ideia organizadora central, o enquadramento. Os pacotes oferecem um número de símbolos condensados que sugerem 0 cerne do enquadramento.

Os autores dividem os dispositivos simbólicos entre os de enquadramento (framing devices) e os de justificação (reasoning devices). 0s primeiros sugerem como pensar sobre uma questão ou fornecem a estrutura para "ler" o tema. Os últimos justificam o que deveria ser feito sobre esse dado assunto, fornecem argumentos ou razões. Os dispositivos de enquadramento são: 1) as metáforas; 2) os exemplos; 3) os slogans ou chavões; 4) as representações e 5) as imagens visuais. Já os dispositivos de justificação são: 1) as origens ou causas; 2) as consequências ou possíveis efeitos; 3) e 0 apelo a princípios. Conforme Gamson e Modigliani (1989), o pacote 
interpretativo pode ser resumido em uma matriz de assinatura que estabelece 0 enquadramento.

Essa matriz tem oito diferentes tipos de elementos - os dispositivos - que sugerem esse cerne de maneira condensada. Nesse sentido, os pacotes implicam uma faixa de posições mais do que um único grupo fechado de símbolos. Em outras palavras, é possível revelar o pacote como um todo através das metáforas, dos slogans ou de outros dispositivos que encontramos no texto. Entre aqueles textos que compartilham o mesmo enquadramento - o princípio mais abstrato e geral -, é possível admitir certo nível de controvérsia, já que eles não precisam ser 100\% compatíveis, mas, sim, possuírem como cerne uma ideia semelhante. Na próxima seção, indicaremos com mais detalhes o modo pelo qual aplicamos metodologicamente a noção de pacotes interpretativos em nosso estudo.

\section{Metodologia: análise indireta de enquadramentos da mídia}

Matthes e Kohring (2008) sugerem uma metodologia que se aproxima da noção de pacotes interpretativos quando desmembram 0 enquadramento em elementos, que, em conjunto, fornecem os padrões de entendimento. Segundo os autores,

Esses elementos não são palavras, mas componentes ou dispositivos dos enquadramentos previamente definidos. Ao invés de codificar diretamente 0 enquadramento como um todo, nós sugerimos partir o enquadramento em seus elementos isolados, os quais podem ser mais facilmente codificados em uma análise de conteúdo. Depois disso, uma análise dos agrupa- mentos desses elementos deve revelar os enquadramentos. Isso significa que quando alguns elementos agrupam-se sistematicamente de uma forma específica, eles formam um padrão que pode ser identificado através de diversos textos em uma amostra. (MATTHES; KOHRING, 2008, p. 263,tradução nossa)

Esses autores, para caracterizar o enquadramento, partem da definição dada por Entman (1993, p. 52 , grifos do autor, tradução nossa), que afirma que enquadrar é "[...] selecionar alguns aspectos $d a$ realidade percebida e fazê-los mais salientes em um texto comunicacional, de forma a promover uma definição particular para o problema, uma interpretação causal, uma avaliação moral e/ou uma recomendação de tratamento." Assim, eles consideram os seguintes elementos para definir 0 enquadramento: definição particular do problema que se subdivide em atores e subtópicos -, causas, julgamentos morais e soluções. Contudo, Matthes e Kohring (2008) indicam que o método não só poderia ser aplicado à definição de Entman, como a qualquer outra que indique os elementos dos frames. Os elementos de Entman $(1993,2004)$ têm função semelhante aos dispositivos de justificaçãa de Gamson e Modigliani (1989), porém, ganham em clareza empírica com a aplicação de Matthes e Kohring (2008). Assim, optamos por utilizálos em nossa matriz de assinatura como nossos dispositivos de justificação.

0 tema da deficiência nos apontou a necessidade de acrescentarmos dois elementos que não fazem parte da lista apresentada acima. Adicionamos os dispositivos rubrica - que diz da seção do 
veículo em que é publicada a notícia - e termos

- que especifica a nomenclatura utilizada para

fazer menção à pessoa com deficiência. A rubrica

fez parte da definição particular do problema,

juntamente com os atores e os subtópicos, e 0

elemento termos foi acrescentado aos framing

devices de Gamson e Modigliani (1989). ${ }^{4}$ Abaixo,

apresentamos nosso quadro de elementos de

enquadramento ou nossa matriz de assinatura que

foi utilizada para a análise empírica das notícias: ${ }^{5}$

\subsection{Amostra e unidade de análise}

Nossa amostra empírica é formada por notícias

publicadas nos jornais Folha de São Paulo e $O$

Globo, pois, dentre as publicações que integram 0 acervo da Fundação Biblioteca Nacional - onde é possível a recuperação das edições mais antigas de jornais do país -, estes são os de maior tiragem e importância no cenário brasileiro. Também fez parte de nossa amostra a revista Veja, publicação de maior tiragem em seu seguimento e também a mais antiga entre as revistas que estão em circulação no mesmo formato no Brasil. Além disso, em 2009, a Veja passou a disponibilizar em seu site 0 acesso digital completo a todas as edições da publicação desde 1968, ano de sua fundação, o que simplificou a coleta do material.

Com relação ao recorte temporal, optamos por resgatar a história dos conceitos associados à ideia da deficiência, a partir do momento em que a questão passa a ser tematizada publicamente no Brasil. Desta forma, nossa análise se estendeu de 1960 até $2008 .{ }^{6}$ Contudo, seria impossível

Quadro 1 - Elementos de enquadramento/Matriz de assinatura

\begin{tabular}{|l|l|}
\hline \multicolumn{1}{|c|}{ Framing devices } & \multicolumn{1}{c|}{ Variáveis situacionais } \\
\hline - metáforas & - definição particular do problema \\
- exemplos & (atores, subtópicos e rubricas) \\
- slogans & - causas \\
- representações & - julgamentos morais \\
- imagens visuais & - soluções \\
- termos & \\
\hline
\end{tabular}

No caso deste tema, o fato de a notícia estar publicada no caderno de Saúde ou no de Política corrobora para a construção de uma rede de sentidos específica. Entretanto, na análise de um escândalo político, por exemplo, não teria grande utilidade a adição do elemento rubrica. Assim, ressaltamos que, menos que uma matriz fixa de elementos, essa matriz de assinatura precisa ser avaliada, levando em conta o tipo de material da análise, o formato do conteúdo e mesmo a temática em questão.

Os procedimentos metodológicos adotados na pesquisa são discutidos detalhadamente em Vimieiro e Maia (2011).

Esse período foi completamente coberto pelo jornal 0 Globo, cuja primeira edição é da década de 20 , e também pela Folha de São Paulo. A revista Veja entra na pesquisa a partir do ano de 1968, quando ela é lançada. 
realizar nossa pesquisa através da seleção de

todas as notícias sobre deficiência publicadas ao longo de 48 anos, principalmente porque grande parte desse material não estava digitalizado.

Sendo assim, optamos por selecionar alguns anos desse período. ${ }^{7}$ Dividimos o corpus em períodos de intervalo de oito anos e fizemos a busca em dois meses de cada ano dos dois jornais - 1960 , 1968, 1976, 1984, 1992, 2000 e 2008. A escolha pelos meses foi feita de forma a compor um ano e dois meses, começando pelos meses de julho e agosto em $1960 .^{8}$ No caso da revista, a busca se deu no conteúdo dos 12 meses desses mesmos anos, já que o conteúdo estava digitalizado e não seria preciso fazer a busca manual pelas notícias - processo necessário no caso da Folha de São

Paulo e de $O$ Globo. ${ }^{9}$

Após a clipagem manual no material não digitalizado e a busca digita ${ }^{10}$ por matérias que tratassem do tema na parte da amostra digitalizada, encontramos 364 textos. Nossa unidade de análise foi a notícia devido à extensão de nosso corpus e tempo de realização da pesquisa.

\subsection{Codificação}

Nossa análise foi feita em etapas. Em um primeiro momento, criamos os códigos referentes aos elementos indicados como os definidores do enquadramento. Nesse estágio, contamos com as informações retiradas de outros estudos sobre deficiência e com a leitura aprofundada de todo o material da análise para a listagem exaustiva dos itens de cada elemento. Essa primeira leitura indica as categorias de nosso codebook, com o desdobramento de variáveis tais como, "exemplos", nos diversos itens acionados nas notícias. Posteriormente, esses itens foram aglutinados quando similares. Nesse sentido, cabe mencionar, numa primeira lista de códigos do dispositivo julgamentos morais, por exemplo, figuravam 48 tipos distintos de julgamentos, que, posteriormente, se transformaram em 12 , através da junção de itens empíricos similares. Essa lista de códigos foi feita e refeita diversas vezes.

É importante ressaltar que, em muitos momentos, não foi possível a redução acentuada dos itens, já que eles não podiam ser unidos por serem absolutamente distintos. Por isso mesmo, no

Essa decisão de seleção da amostra levou em conta uma série de empecilhos para a definição da mesma que o estudo teve de enfrentar. Para mais detalhes, consultar Vimieiro (2010).

Edições que estavam em bom estado de conservação no acervo da Biblioteca Nacional.

0 material da Folha de São Paulo de 1960 a 1994 não estava digitalizado quando da realização da pesquisa - ele foi disponibilizado formato digital apenas no início de 2011 -, motivo pelo qual fizemos a busca manual por notícias sobre esse assunto no acervo da Biblioteca Nacional. 0 material de 0 Globo de 1960 a 1997 também não estava digitalizado. 0 mesmo procedimento foi adotado com relação aos anos selecionados que se encontravam neste intervalo de tempo.

Entre palavras e expressões comumente utilizadas para fazer menção à pessoa com deficiência ou algum tipo específico de deficiência ou ainda siglas e nomes de entidades popularmente reconhecidas como atuantes nesse assunto, nossa pesquisa abarcou 158 itens de busca. 
cruzamento dos dados, desconsideramos

aqueles itens que não tivessem a recorrência

mínima de 5\%, seguindo a estratégia adotada por

Matthes e Kohring (2008). Assim, quando alguns

itens não podiam ser agrupados para aumentar

a reincidência e, desta forma, se tornarem

dados relevantes, eles permaneciam separados

e, então, no cruzamento dos dados, eram

desconsiderados. Na lista de códigos final, cada

elemento de enquadramento teve 0 seguinte

número de itens: ${ }^{11}$

Exemplos: 36

Slogans: 34

Termos: 11

Atores: 21

Subtópicos: 18

Rubricas: 18

Causas: 15

Soluções: 19

Julgamentos Morais: $12^{12}$

Por fim, fizemos um teste de confiabilidade da

codificação da amostra em 10\% dos textos. Este

teste analisa a codificação feita por dois ou mais codificadores para perceber o nível de

concordância entre eles. Alcançamos o índice

de 0.70 de concordância na codificação feita por

dois codificadores, em 10\% da amostra.

\subsection{Cruzamento dos dados}

Depois da codificação do material, os dados foram processados por um software que utiliza algoritmos de agrupamento, o RapidMiner, software livre de mineração de dados. 0

software agrupa aquelas notícias que têm elementos parecidos, formando conjuntos os mais similares internamente. 0 agrupamento também procura formar conjuntos os mais distintos uns dos outros. Assim, em cada época da trajetória discursiva mediada, o software agrupou notícias com padrões semelhantes, que fornecem grupos com elementos recorrentes em comum.

Apresentamos abaixo um exemplo do tipo de resposta que o software nos fornecia. Observe os resultados retornados no cruzamento dos dados de 1984:

Como é possível perceber, alguns elementos de enquadramento enumerados em nossa matriz de assinatura não foram listados aqui. As variáveis metáforas, representações e imagens visuais foram retiradas de nossa análise posteriormente à definição da matriz de elementos. A primeira pela baixa ocorrência nos textos analisados, a segunda pela dificuldade de identificação objetiva e clara e a terceira por problemas técnicos que tivemos em parte da amostra. Elas foram retiradas deste cruzamento de dados, mas podem contribuir para a identificação dos enquadramentos em outros estudos.

0 elemento slogans, por exemplo, se converteu em uma lista como essa: 1) Que ressaltam a necessidade de se ajudar a pessoa com deficiência, com expressões como "é preciso carinho e compreensão no cuidado com a pessoa com deficiência", "a pessoa com deficiência não pode ser abandonada" ou ainda "a pessoa com deficiência pode ser ajudada"; 2) Que indicam a necessidade da pessoa com deficiência superar a deficiência. É quase uma busca incessante por cura, por ser normal, ou o mais próximo possível; 3) Que indicam a necessidade ou a ideia de preparação para viver na sociedade, como as ideias de "integração", "recuperação", "reabilitação", "readaptação" ou "reeducação"; [...]. A tabela 1 (Grupos formados em 1984), apresentada abaixo, também fornece alguns exemplos das variáveis que compunham cada categoria. As tabelas completas com as variáveis de todas as categorias estão disponíveis em Vimieiro (2010). 
Tabela 1 - Grupos formados em 1984

\begin{tabular}{|c|c|c|c|}
\hline $\begin{array}{l}\text { Número de notícias } \\
\text { do grupo }\end{array}$ & $\begin{array}{l}\text { Elemento de } \\
\text { enquadramento }\end{array}$ & Item empírico do elemento & $\begin{array}{l}\text { Reincidência nas notícias } \\
\text { desse grupo }\end{array}$ \\
\hline \multirow{5}{*}{26} & Causa & $\begin{array}{l}\text { Foco no aspecto físico. } 0 \text { problema é } \\
\text { visto como corporal, a deficiência em si }\end{array}$ & $69 \%$ \\
\hline & Termos & Técnicos ou oriundos da medicina. & $57 \%$ \\
\hline & Subtópico & Medicina I Saúde I Ciência I Tecnologia & $57 \%$ \\
\hline & Solução & $\begin{array}{l}\text { Está na medicina, na área da saúde, } \\
\text { através de cirurgias, próteses, } \\
\text { transplantes ou então na ciência, } \\
\text { através de pesquisa. }\end{array}$ & $53 \%$ \\
\hline & Atores & Campo médico I Saúde & $46 \%$ \\
\hline \multirow{9}{*}{11} & Subtópicos & Cidadania | Direitos | Questões legais & $81 \%$ \\
\hline & Termos & $\begin{array}{l}\text { Que focam na deficiência em si e não na } \\
\text { incapacidade para certas atividades. }\end{array}$ & $72 \%$ \\
\hline & Slogans & $\begin{array}{l}\text { Que ressaltam a noção de direitos e de } \\
\text { cidadania, de reconhecimento, de luta contra } \\
\text { injustiças, ou que falam de leis, de políticas } \\
\text { afirmativas etc. }\end{array}$ & $63 \%$ \\
\hline & Causa & $\begin{array}{l}0 \text { problema é visto sob o ponto de vista legal, } \\
\text { como problemas com a legislação vigente ou } \\
\text { requisição de direitos. }\end{array}$ & $54 \%$ \\
\hline & Solução & $\begin{array}{l}\text { Passa por mudanças legais, como edição de } \\
\text { novas leis ou modificação das já existentes, } \\
\text { ou pela concessão de direitos já adquiridos } \\
\text { etc. }\end{array}$ & $45 \%$ \\
\hline & Solução & $\begin{array}{l}\text { A solução está na ação do Estado para } \\
\text { resolver problemas, seja através de medidas } \\
\text { governamentais ou investimento público. }\end{array}$ & $45 \%$ \\
\hline & Rubrica & $\begin{array}{l}\text { Geral | Cotidiano | Grande Rio | Bairros | } \\
\text { Interior }\end{array}$ & $45 \%$ \\
\hline & $\begin{array}{l}\text { Julgamento } \\
\text { moral }\end{array}$ & $\begin{array}{l}\text { Deficiência sendo associada a julgamentos, } \\
\text { sentimentos ou características negativos. }\end{array}$ & $45 \%$ \\
\hline & Causa & $\begin{array}{l}0 \text { foco do problema é a questão financeira, } 0 \\
\text { déficit em assistência. }\end{array}$ & $45 \%$ \\
\hline
\end{tabular}


Por esse tipo de informação, fornecida pelo software no cruzamento dos dados de cada ano, é que nossa análise se guiou. A partir das características mais marcantes dos grupos, analisamos 0 ambiente sócio-histórico para nomearmos os enquadramentos de cada conjunto.$^{13}$ No caso do exemplo acima, o grupo de 1984 que tem 26 notícias foi nomeado como enquadramento médico e o que contém 11 textos foi chamado de conjunto do enquadramento dos direitos. 0s grupos dos outros anos também foram nomeados segundo as características recorrentes. Alguns enquadramentos ocorreram em mais de um ano e a nomeação de grupos de anos distintos como sendo do mesmo enquadramento levou em conta a proximidade das características marcantes dos conjuntos.

\section{Resultados empíricos}

Abaixo, apresentamos o gráfico geral de enquadramentos por ano, com a porcentagem de notícias daquele frame no universo de textos do respectivo ano:

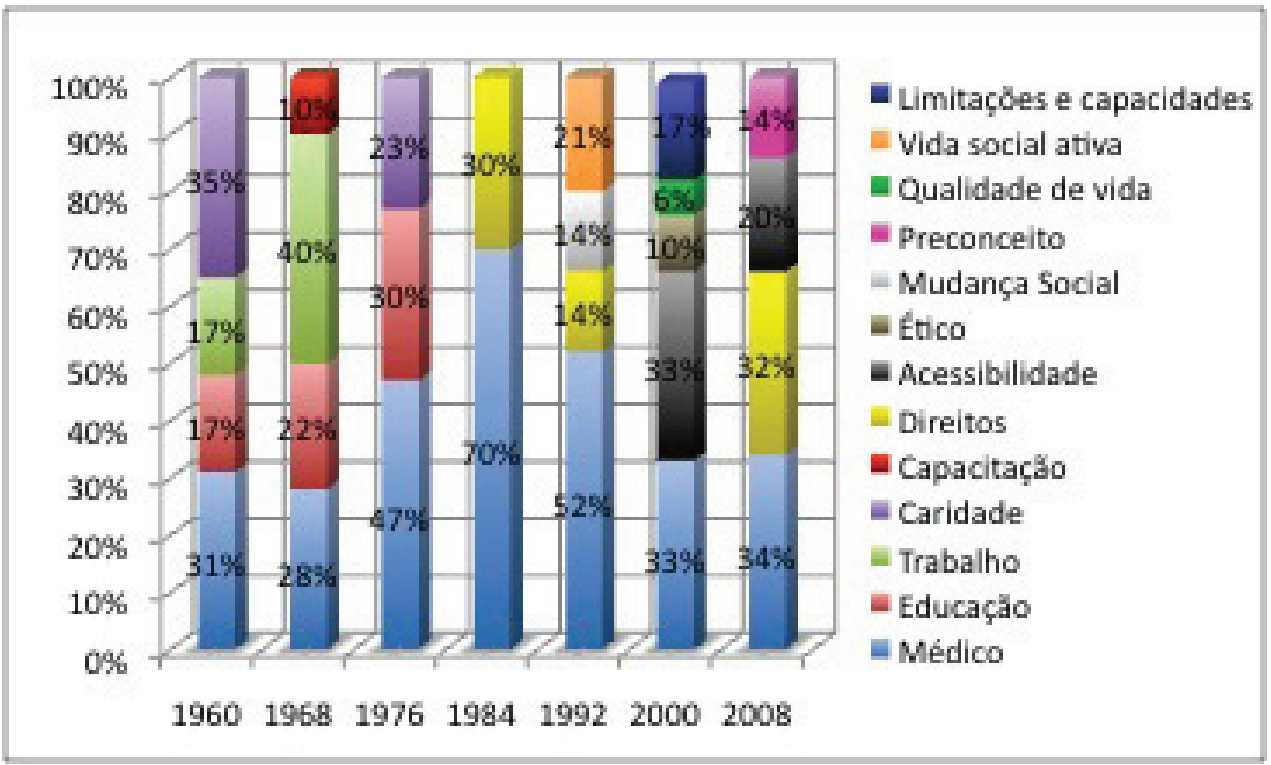




\subsection{Análise dos resultados}

Fomos guiados na análise dos dados por duas questões principais, que são o foco deste artigo: a)

Os resultados encontrados por esta pesquisa são claramente distintos dos resultados encontrados pela pesquisa da Rede ANDI. Como explicar tal distinção? b) Podemos pensar em um processo de aperfeiçoamento ético-moral ao longo dos anos? Passemos à primeira pergunta.

\subsubsection{Como explicar a distinção entre os resultados encontrados nesta pesquisa $\mathrm{e}$ os do estudo da ANDI?}

Algumas questões devem ser esclarecidas antes de explorarmos as razões da distinção dos resultados encontrados em nossa pesquisa e aqueles apresentados pela ANDI. Sinteticamente, podemos dividir a trajetória discursiva mediada sobre o tema da deficiência em duas fases. Uma primeira que vai de 1960 a 1976, e que é marcada por enquadramentos que remetem ao modelo integrativo, o comportamento caridoso com relação à pessoa com deficiência e a uma perspectiva médica acerca do assunto. E uma segunda fase, que se inicia em 1984 e tem como característica significativa 0 surgimento de uma perspectiva de direitos, além de noções relacionadas ao ideal inclusivo ganharem expressão através dos enquadramentos da acessibilidade, da qualidade de vida, das limitações e capacidades, do preconceito ${ }^{14}$ etc.
A primeira fase é o período de auge do que chamamos de tripé educação/saúde/trabalho. Essas eram as alternativas para as pessoas com deficiência nesta época. Elas podiam receber tratamento médico, serem educadas em escolas especiais ou passarem por reabilitação profissional que lhes possibilitasse atividade laboral. Por isso mesmo são esses os enquadramentos predominantes nesta fase.

Todavia, é preciso ressaltar aqui que as noções de educação e de trabalho presentes nas notícias são bastante limitadas.

0 enquadramento da educação delimita claramente que a ideia é que as pessoas com deficiência devem ser educadas para "parecerem normais"; que elas devem passar por esse processo de preparação em separado; que há uma distinção clara entre o que é o normal e a deficiência. Enfim, não é simplesmente uma ideia de educação, não é um tema. É um enquadramento, uma forma específica de entendimento, que é delimitada a partir das variáveis recorrentes nos grupos nomeados como pertencentes ao enquadramento da educação. A ideia de preparação para viver em sociedade advém, por exemplo, dos slogans recorrentes nos grupos de 1960 e 1976 desse enquadramento - expressões como "reeducação", "recuperação", "reabilitação" e "integração" são reincidentes. 
A noção de trabalho pressupõe a ideia de que esses indivíduos precisam retornar à produtividade, deixarem de ser um peso morto para a sociedade. Para isso, eles precisam ser treinados, reabilitados para, então, desenvolverem uma atividade laboral, que, na maioria das vezes, se restringe à atuação em uma oficina protegida. Ou seja, também é uma noção restrita de trabalho, na medida em que se preocupa apenas em devolver a ideia de utilidade a essas pessoas.

Em contraste, a segunda fase começa justamente com o surgimento de uma perspectiva de direitos. Esse enquadramento aparece em um primeiro momento não exatamente atrelado ao ideal da inclusão, mas sim como uma colocação efetiva do problema num nível do Estado. Aliás, a ocorrência de julgamentos negativos - apontada no exemplo acima do grupo dos direitos de 1984 - ressalta que essa noção de direitos não era exatamente uma noção inclusiva, já que a pessoa com deficiência era vista como alguém que sofria. É preciso também mencionar que o surgimento deste enquadramento faz parte de um processo. Por isso, a análise a longo prazo é tão útil para percebermos certas transformações.

A pesquisa da ANDI foi conduzida tendo como parâmetro de análise justamente esse ideal inclusivo, o que significa que 0 estudo traçou critérios para a análise do material que funcionam como requisitos deontológicos. Ou seja, eles criaram uma série de critérios, baseados no ideal inclusivo, que as notícias teriam que alcançar.
Este tipo de análise, que traça padrões muitas vezes rígidos e que partem de uma noção contemporânea exigente de mudança social - a ideia de inclusão -, tende quase sempre a encontrar um resultado muito aquém das expectativas dos pesquisadores. Além disso, 0 viés militante do estudo, pró-inclusão, também acaba por levar a uma análise que reprova certos resultados na medida em que eles não condizem exatamente com o que idealmente se traçou como inclusão.

A integração, como já explicitamos, pressupõe um processo de preparação das pessoas com deficiência para a vida em sociedade. Já 0 ideal inclusivo parte da ideia de inserção total e incondicional e pressupõe uma ruptura nesses mesmos sistemas. Isso porque o ideal inclusivo exige transformações profundas, mudanças que beneficiariam toda e qualquer pessoa. $0 u$ seja, ele trabalha sob a "ética da diversidade" (WERNECK, 2003), em que não há um grupo específico que ganha com determinadas medidas, mas sim a noção de que todos ganham com medidas que acolhem as necessidades de qualquer pessoa - com deficiência, idosos etc. É uma noção de direitos de todas as pessoas.

Esse modelo carrega uma série de conceitos sobre a questão da deficiência como vida independente, equiparação de oportunidades, acessibilidade etc. e utiliza 0 adjetivo inclusivo quando se busca qualidade para todas as pessoas com e sem deficiência (escola inclusiva, trabalho inclusivo, 
lazer inclusivo etc.). 0 movimento inclusivo tem posições radicais que não são compartilhadas por todas as pessoas com deficiência e nem por suas entidades representativas - nesse sentido, podemos mencionar os embates, por exemplo, entre entidades pró-inclusão e a Apae. Pelo contrário, o movimento inclusivo é uma espécie de movimento específico, que tem bastante força e repercussão, mas cujo ideal não é completamente compartilhado mesmo entre as pessoas com deficiência.

Essa série de condições para definir o que é inclusão cria um entrave na análise feita pela ANDI, na medida em que, para ser inclusivo, o conteúdo noticioso precisava cumprir rigorosamente a praticamente todos esses valores, embutidos numa forma bastante ampla e radical de pensamento. Essa necessidade de uma congruência integral a todos os valores acaba por obscurecer a presença de alguns sentidos ligados à inclusão, na medida em que eles não aparecem de forma tão bem articulada. Além disso, a análise pontual também ajuda a obscurecer a presença desses valores, pois eles não têm como se destacar por se diferenciarem dos panoramas de sentidos encontrados em outros anos.

Nesse sentido, a diferenciação que Peters (2008) faz de interpretações gerais e coletivas pode ajudar a explicar esse não aparecimento por completo do ideal inclusivo na mídia. Nesse sentido, a pesquisa parece indicar que o ideal inclusivo é bastante compartilhado por uma identidade coletiva específica, que não é composta por todas as pessoas com deficiência e suas entidades representativas. Esse ideal, em seu sentido completo, não ultrapassou ainda os muros dessa coletividade, não se tornou interpretação geral, ainda que tenha sido instituído legalmente. Isso porque a simples mudança legal, a tomada de decisão num sentido, não tem como consequência automática a mudança da cultura pública geral. Passemos à segunda pergunta.

\subsubsection{Podemos pensar em um processo de aperfeiçoamento ético-moral com relação à temática da deficiência?}

0 fato de 0 ideal inclusivo não estar presente em sua completude na mídia não significa que não observamos um processo de profunda modificação na cultura pública relativa à deficiência. 0 que chamamos aqui de processo de aperfeiçoamento ético-moral se relaciona com a noção de luta moralmente motivada, na acepção proposta por Honneth (2003a). Ancorado nas ideias do pragmatista Mead e de Hegel, Honneth desenvolve uma teoria da sociedade que busca explicar os processos de mudança social recorrendo às pretensões normativas estruturalmente inscritas na relação de reconhecimento recíproco. A teoria do reconhecimento de Honneth dá à luta social 0 papel de força estruturante na evolução moral da sociedade.

Honneth (2003a) caracteriza o processo de evolução moral como uma cadeia histórica de 
ideais normativos que apontam na direção de um crescimento em autonomia pessoal dos sujeitos ou de ampliação da inclusão social. Honneth (2003b, p.184-185) especifica dois critérios que permitem falar em progresso moral nas relações de reconhecimento. São eles: a) graus mais elevados no processo de individualização, isto é, "[...] 0 aumento de oportunidades para que alguém possa legitimamente articular partes de uma personalidade" e b) ampliação do processo de inclusão social, isto é "[...] expansão da inclusão de sujeitos no círculo de membros integrais da sociedade".

Honneth (2003c, p. 250) diferencia esse processo de reconhecimento moralmente motivado em três esferas (de relações íntimas, de relações legais e de relações sociais), constituídas por diferentes princípios normativos: 0 do amor, o do direito e 0 da solidariedade. Esses princípios normativos não são arbitrários ou estáticos, mas, ao invés disso, historicamente constituídos; eles determinam "[...] 0 horizonte linguístico de pensamentos sócio-morais e os sentimentos de uma sociedade particular". De tal modo, Honneth (2003b, p. 143) propõe que tais princípios produzem a referência para que os sujeitos possam contestar e argumentar razoavelmente que "[...] as formas existentes de reconhecimento são inadequadas ou insuficientes e precisam ser expandidas".

Para nossos propósitos, interessa explorar a dimensão do direito para explicitar o processo de aperfeiçoamento ético-moral no caso da questão da deficiência. A própria noção de reconhecimento jurídico em si, diz Honneth (2003a), só pôde se constituir na sequência de uma evolução histórica. Essa evolução remete à transição do direito ligado à tradição para o direito pós-tradicional. Nas relações jurídicas tradicionais, o reconhecimento como pessoa de direito ainda está fundido ao status social. Esse nexo, diz Honneth (2003a, p. 188), se dissolve a partir da distinção da noção de respeito ligada ao reconhecimento jurídico e outra relacionada à estima social. A partir do momento que 0 direito assume feições pós-tradicionais e se desliga das atribuições de status, ele tem como tarefa "[...] proteger e possibilitar não somente a posse, mas também o exercício daquela capacidade universal que caracteriza o ser humano como pessoa".

Essa propriedade universal, que se define pela nova forma de legitimação do direito moderno, é a assunção de imputabilidade moral de todos os seus membros. Tal atribuição não designaria nenhuma propriedade que tenha contornos claros, mas indica que as capacidades pelas quais os membros de uma sociedade se reconhecem mutuamente podem se modificar se eles não respeitam uns aos outros como pessoas de direito. Daí que

A ampliação cumulativa de pretensões jurídicas individuais, com a qual temos que lidar em sociedades modernas, pode ser entendida como um processo em que a extensão das propriedades universais de uma pessoa moralmente imputável foi aumentando passo a passo, visto que, sob a pressão de uma luta por reconhecimento, devem ser sempre adicionados novos pressupostos para a participação na formação racional da vontade (HONNETH, 2003a, p. 189). 
No que concerne à trajetória discursiva mediada da questão da deficiência, o surgimento de uma perspectiva de direitos na década de 80 indica uma diferença crucial com relação ao período anterior, marcado pelo tripé educação/saúde/ trabalho. A partir da década de 80, podemos perceber que há uma guinada nas notícias que apontam para a luta das pessoas com deficiência por melhores condições de vida, através da busca por direitos que assegurem na prática tais condições. Seja através da luta por processos mais ampliados e irrestritos socialmente de reabilitação, pela eliminação de barreiras que impedem suas atividades diárias ou por oportunidades efetivas de trabalho que não se resumam a oficinas protegidas. A busca por graus maiores de individualização, em que as pessoas com deficiência possam desempenhar as atividades diárias sem ter de esbarrar em condições que os impedem de ter uma vida social e profissional ativa está presente nas notícias a partir de 1984. Fica claro nos textos que não é mais a deficiência em si que é vista como empecilho para a participação efetiva nos processos sociais. E é em busca da eliminação dessas barreiras, sejam elas físicas, culturais ou econômicas, que as pessoas com deficiência passam a ganhar voz e lutarem por direitos também no ambiente midiático.

Esse processo, se partirmos do princípio normativo que orienta o reconhecimento jurídico para Honneth (2003a), pode ser interpretado como um evidente processo de evolução moral.
Ao narrar historicamente o modo pelo qual se dá a ampliação sucessiva dos direitos individuais fundamentais, Honneth (2003a) indica a importância não só da proteção jurídica em si, mas também das condições necessárias para a participação igual num acordo racional. É nesse sentido que, historicamente, acrescentouse às propriedades que colocam um sujeito em condições de agir autonomamente com discernimento racional uma medida mínima de formação cultural e de segurança econômica, uma vez que "[...] um sujeito é respeitado se encontra reconhecimento jurídico não só na capacidade abstrata de poder orientar-se por normais morais, mas também na propriedade concreta de merecer o nível de vida necessário para isso" (HONNETH, 2003a, p. 193). Visualiza-se, assim, que na primeira fase desse processo encontrávamos notícias que focavam na caridade e na questão da educação/saúde/trabalho, mas não demonstravam a busca do reconhecimento jurídico das pessoas com deficiência como moralmente imputáveis. Nem mesmo voz essas pessoas tinham nas notícias. Muitas vezes, nesse primeiro período, são os pais ou outros profissionais relacionados ao assunto que falam sobre a questão aos jornais. Vinte anos depois, as pessoas com deficiência passam a se expressar publicamente e buscam mais que simplesmente se reabilitarem para um mundo despreparado para recebê-las. Elas buscam a melhoria do acesso, ou seja, das condições que possibilitam que elas sejam reconhecidas como sujeitos de direito, que podem 
participar da formação da vontade pública, desde que tenham condições práticas para tal. Assim, percebemos que há um processo de aprendizado social, em que não só as pessoas com deficiência buscam reconhecimento. Elas efetivamente começam a ser reconhecidas intersubjetivamente como pessoas de direito pela comunidade, o que não ocorria na primeira fase da trajetória, quando elas ainda eram vistas como "dignas de pena" - como vemos no enquadramento da caridade, por exemplo. As pretensões jurídicas dessas pessoas recebem consideração e elas, a partir da experiência do autorrespeito, desencadeada pelo reconhecimento jurídico, são capazes de vê-las positivamente já no final da segunda fase da trajetória, como revelam os julgamentos morais positivos presentes nas notícias mais recentes década de 90 e anos 2000.

\section{Considerações finais}

0 objetivo deste trabalho foi traçar, a partir dos enquadramentos encontrados no conteúdo jornalístico, a cultura pública mediada sobre o tema da deficiência de 1960 a 2008. Posteriormente, analisamos esta trajetória a partir de questões específicas, relacionadas sobretudo às diferenças de resultado encontradas nesta pesquisa a longo prazo e no estudo específico desenvolvido pela Rede ANDI. Argumentamos que a análise a longo prazo identifica 0 surgimento de uma perspectiva de direitos, a partir dos anos 80, e também aponta para fases bastante distintas, em termos de interpretações públicas sobre 0 assunto, nas décadas passadas e atualmente. Ainda que o ideal inclusivo não esteja presente em sua completude e em seu escopo mais exigente de mudanças institucionais e sociais, indicamos que valores inclusivos ganham expressão midiática. Também explicitamos que é possível perceber um processo de aprendizado social, sobretudo se analisamos as mudanças no âmbito jurídico. Este processo de aperfeiçoamento ético-moral ganha força com a luta moralmente motivada desencadeada nos anos 80 pelos movimentos sociais e outras organizações da sociedade civil relacionadas ao assunto.

\section{Referências}

BOHMAN, J. Public deliberation: pluralism, complexity and democracy. Cambridge: MIT, 2000.

CERIGNONI, F. N.; RODRIGUES, M. P. Deficiência: uma questão política? São Paulo: Paulus, 2005.

CHAMBERS, S. Reasonable democracy: Jurgen Habermas and the politics of discourse. Ithaca: Cornell University Press, 1996.

CORRER, R. Deficiência e inclusão social: construindo uma nova comunidade. Bauru: EDUSC, 2003. . Legitimidade e economia na democracia deliberativa. In: COELHO, V. S. P.; NOBRE, M. (Ed.). Participação e deliberação: teoria democrática e experiências institucionais no Brasil contemporâneo. São Paulo: Ed. 24, 2004. p. 41-62. 
DRYZEK, J. S. The politics of the earth:

environmental discourses. New York: Oxford University Press, 1997.

Legitimidade e economia na democracia deliberativa. In: COELHO, V. S. P.; NOBRE, M.

(Ed.). Participação e deliberação: teoria democrática e experiências institucionais no Brasil contemporâneo. São Paulo: Ed. 24, 2004. p. $41-62$.

ENTMAN, R. M. Framing: Toward clarification of a fractured paradigm. Journal of

Communication, v. 43, n. 4, p. 51-58, 1993.

Projections of power: framing news, public opinion, and U.S. foreign policy. Chicago: The University of Chicago Press, 2004.

\section{FÁVERO, E. A. G. Direitos das pessoas com}

deficiência: garantia de igualdade na diversidade. Rio de Janeiro: WVA, 2004.

GAMSON, W.; MODIGLIANI, A. Media discurse and public opinion on nuclear power: a construcionist approach. American Journal of Sociology, v. 95, p. 1-37, 1989.

GAMSON, W. A. Talking politics. Cambrigde: Cambridge University Press, 1992.

GITLIN, T. The whole world is watching: mass media in the making \& unmaking of the new left. Berkeley: University of California Press, 1980.

GOFFMAN, E. Frame analysis: an essay on the organization of experience. Cambrigde: Harvard
University Press, 1974.

GOMES, W. Da discussão à visibilidade. In: GOMES, W.; MAIA, R. C. M. (Ed.). Comunicação e democracia: problemas e perspectivas. São Paulo: Paulus, 2008. p. 117-162.

HABERMAS, J. Direito e democracia: entre facticidade e validade - vol.II. Rio de Janeiro: Tempo Brasileiro, 1997.

HONNETH, A. Luta por reconhecimento: a gramática moral dos conflitos sociais. São Paulo: Ed. 34, 2003a.

Redistribution as recognition: a response to Nancy Fraser. In: FRASER, N; HONNETH, A. Redistribution or recognition? A politicalPhilosophical exchange. Londres; Nova York: Verso, 2003b. p. 110-197.

The point of recognition: a rejoinder to the rejoinder. In: FRASER, N; HONNETH, A. Redistribution or recognition? A politicalphilosophical exchange. Londres; NY: Verso, 2003c. p. 237-267.

MAIA, R. C. M. Dos dilemas da visibilidade midiática para deliberação pública. In: LEMOS, A. et al. (Ed.). Mídia.BR. Porto Alegre: Sulina, 2004. p. 9-38. Livro da XIII Compós. Visibilidade midiática e deliberação pública. In: GOMES, W.; MAIA, R. C. M. (Ed.). Comunicação e democracia: problemas e perspectivas. São Paulo: Paulus, 2008. p. 165-194. 
MATTHES, J.; KOHRING, M. The content analysis of media frames: Toward improving reliability and validity. Journal of Communication, v. 58, n. 2, p. 258-279, 2008.

PETERS, B. On public deliberation and public culture. In: WESSLER, H. (Ed.). Public

deliberation and public culture: the writings of Bernhard Peters, 1993-2005. Basingstoke, Hampshire: Palgrave Macmillan, 2008. p. 68-118.

VIMIEIRO, A. C. Cultura pública e aprendizado social: a trajetória dos enquadramentos sobre a temática da deficiência na imprensa brasileira (1960-2008). 2010. 233 f. Dissertação (Mestrado em Comunicação) - Faculdade de Filosofia e Ciências Humanas, Universidade Federal de Minas Gerais, Belo Horizonte, 2010. Disponível em: < http://bit.ly/g97z6s > . Acesso em: 14 jun. 2011.

VIMIEIR0, A. C.; MAIA, R. C. M. Análise indireta de enquadramentos da mídia: uma alternativa metodológica para a identificação de frames culturais. Revista FAMECOS, v. 18, p. 235-252, 2011. Disponível em: < http://revistaseletronicas. pucrs.br/ojs/index.php/revistafamecos/article/ view/8810 > Acesso em: 22 jul. 2011

VIVARTA, V. Mídia e deficiência. Brasília: ANDI; Fundação Banco do Brasil, 2003.

WERNECK, C. Você é gente? 0 direito de nunca ser questionado sobre o seu valor humano. Rio de Janeiro: WVA, 2003. 
Media frames and the social learning process: changes in the public culture about the disability issue from 1960 to 2008

\section{Encuadres de los medios y el proceso de adrendizaje social: transformaciones en la cultura pública acerca de el tema de la discapacidad de 1960 a 2008}

\section{Abstract:}

The aim of this paper is to analyze the mediated public culture about the subject of disability from 1960 to 2008 in Brazil. Supported by the analysis of 364 news published in that period by the newspapers Folha de São Paulo and 0 Globo, and by the magazine Veja, the work points out an intense pluralization of frames along the last decades and the strengthening of a perspective of rights that did not have visibility until the eighties. The obtained results contest the skepticism of previous studies about the change of the values related to the topic. Our long-term analysis, while comparing the current media frames to those of the past decades, suggests a deep process of social learning.

\section{Keywords:}

Public culture. Frame. Social learning. Disability. Inclusion.

\section{Resumen:}

El propósito de este trabajo es analisar la cultura pública mediada acerca del tema de la discapacidad de 1960 a 2008, en Brasil. Basados en la análisis de 364 noticias publicadas en este período en los vehículos Folha de São Paulo, 0 Globo y Veja, el estudio indica una intensa pluralización de los encuadres en el curso de las últimas décadas y el fortalecimiento de una perspectiva de derechos que hasta los años 80 no tenía visibilidad. Los resultados obtenidos desafían el escepticismo de estudios anteriores sobre el cambio de los valores relacionados con el tema. Nuestra largo plazo análisis, al comparar los encuadres actuales de los medios con los de décadas pasadas, apunta para un profundo proceso de aprendizaje social.

\section{Palabras clave:}

Cultura pública. Encuadre. Aprendizaje social. Discapacidad. Inclusión. 


\section{Expediente}

A revista E-Compós é a publicação científica em formato eletrônico da Associação Nacional dos Programas de Pós-Graduação em Comunicação (Compós). Lançada em 2004, tem como principal finalidade difundir a produção acadêmica de pesquisadores da área de Comunicação, inseridos em instituições do Brasil e do exterior.

\section{E-COMPÓS I www.e-compos.org.br I E-ISSN 1808-2599}

Revista da Associação Nacional dos Programas de Pós-Graduação em Comunicação.

Brasília, v.14, n.1, jan/abr. 2011

A identificação das edições, a partir de 2008

passa a ser volume anual com três números.

\section{CONSELHO EDITORIAL}

Afonso Albuquerque, Universidade Federal Fluminense, Brasil Alberto Carlos Augusto Klein, Universidade Estadual de Londrina, Brasil Alex Fernando Teixeira Primo, Universidade Federal do Rio Grande do Sul, Brasil Ana Carolina Damboriarena Escosteguy, Pontifícia Universidade Católica do Rio Grande do Sul, Brasil

Ana Gruszynski, Universidade Federal do Rio Grande do Sul, Brasil Ana Silvia Lopes Davi Médola, Universidade Estadual Paulista, Brasil André Luiz Martins Lemos, Universidade Federal da Bahia, Brasil Ângela Freire Prysthon, Universidade Federal de Pernambuco, Brasil Angela Cristina Salgueiro Marques, Faculdade Cásper Líbero (São Paulo), Brasil Antônio Fausto Neto, Universidade do Vale do Rio dos Sinos, Brasil Antonio Carlos Hohlfeldt, Pontifícia Universidade Católica do Rio Grande do Sul, Brasil Antonio Roberto Chiachiri Filho, Faculdade Cásper Líbero, Brasil Arlindo Ribeiro Machado, Universidade de São Paulo, Brasil Arthur Autran Franco de Sá Neto, Universidade Federal de São Carlos, Brasil Benjamim Picado, Universidade Federal Fluminense, Brasil César Geraldo Guimarães, Universidade Federal de Minas Gerais, Brasil Cristiane Freitas Gutfreind, Pontifícia Universidade Católica do Rio Grande do Sul, Brasil Denilson Lopes, Universidade Federal do Rio de Janeiro, Brasil Denize Correa Araujo, Universidade Tuiuti do Paraná, Brasil Edilson Cazeloto, Universidade Paulista, Brasil Eduardo Peñuela Cañizal, Universidade Paulista, Brasil Eduardo Vicente, Universidade de São Paulo, Brasil Eneus Trindade, Universidade de São Paulo, Brasil Erick Felinto de Oliveira, Universidade do Estado do Rio de Janeiro, Brasil Florence Dravet, Universidade Católica de Brasília, Brasil Francisco Eduardo Menezes Martins, Universidade Tuiuti do Paraná, Brasil Gelson Santana, Universidade Anhembi/Morumbi, Brasil Gilson Vieira Monteiro, Universidade Federal do Amazonas, Brasil Gislene da Silva, Universidade Federal de Santa Catarina, Brasil Guillermo Orozco Gómez, Universidad de Guadalajara Gustavo Daudt Fischer, Universidade do Vale do Rio dos Sinos, Brasil Hector Ospina, Universidad de Manizales, Colômbia Herom Vargas, Universidade Municipal de São Caetano do Sul, Brasil leda Tucherman, Universidade Federal do Rio de Janeiro, Brasil Inês Vitorino, Universidade Federal do Ceará, Brasil Janice Caiafa, Universidade Federal do Rio de Janeiro, Brasil Jay David Bolter, Georgia Institute of Technology Jeder Silveira Janotti Junior, Universidade Federal de Pernambuco, Brasil João Freire Filho, Universidade Federal do Rio de Janeiro, Brasil
John DH Downing, University of Texas at Austin, Estados Unidos José Afonso da Silva Junior, Universidade Federal de Pernambuco, Brasil José Carlos Rodrigues, Pontifícia Universidade Católica do Rio de Janeiro, Brasil José Luiz Aidar Prado, Pontifícia Universidade Católica de São Paulo, Brasil José Luiz Warren Jardim Gomes Braga, Universidade do Vale do Rio dos Sinos, Brasil Juremir Machado da Silva, Pontifícia Universidade Católica do Rio Grande do Sul, Brasil Laan Mendes Barros, Universidade Metodista de São Paulo, Brasil Lance Strate, Fordham University, USA, Estados Unidos Lorraine Leu, University of Bristol, Grã-Bretanha Lucia Leão, Pontifícia Universidade Católica de São Paulo, Brasil Luciana Panke, Universidade Federal do Paraná, Brasil Luiz Claudio Martino, Universidade de Brasília, Brasil Malena Segura Contrera, Universidade Paulista, Brasil Márcio de Vasconcellos Serelle, Pontifícia Universidade Católica de Minas Gerais, Brasil Maria Aparecida Baccega, Universidade de São Paulo e Escola Superior de Propaganda e Marketing, Brasil

Maria das Graças Pinto Coelho, Universidade Federal do Rio Grande do Norte, Brasil Maria Immacolata Vassallo de Lopes, Universidade de São Paulo, Brasil Maria Luiza Martins de Mendonça, Universidade Federal de Goiás, Brasil Mauro de Souza Ventura, Universidade Estadual Paulista, Brasil Mauro Pereira Porto, Tulane University, Estados Unidos Nilda Aparecida Jacks, Universidade Federal do Rio Grande do Sul, Brasil Paulo Roberto Gibaldi Vaz, Universidade Federal do Rio de Janeiro, Brasil Potiguara Mendes Silveira Jr, Universidade Federal de Juiz de Fora, Brasil Renato Cordeiro Gomes, Pontifícia Universidade Católica do Rio de Janeiro, Brasil Robert K Logan, University of Toronto, Canadá

Ronaldo George Helal, Universidade do Estado do Rio de Janeiro, Brasil Rosana de Lima Soares, Universidade de São Paulo, Brasil Rose Melo Rocha, Escola Superior de Propaganda e Marketing, Brasil Rossana Reguillo, Instituto de Estudos Superiores do Ocidente, Mexico Rousiley Celi Moreira Maia, Universidade Federal de Minas Gerais, Brasil Sebastião Carlos de Morais Squirra, Universidade Metodista de São Paulo, Brasil Sebastião Guilherme Albano da Costa, Universidade Federal do Rio Grande do Norte, Brasil

Simone Maria Andrade Pereira de Sá, Universidade Federal Fluminense, Brasil Tiago Quiroga Fausto Neto, Universidade de Brasília, Brasil Suzete Venturelli, Universidade de Brasília, Brasil

Valério Cruz Brittos, Universidade do Vale do Rio dos Sinos, Brasil Valerio Fuenzalida Fernández, Puc-Chile, Chile Veneza Mayora Ronsini, Universidade Federal de Santa Maria, Brasil Vera Regina Veiga França, Universidade Federal de Minas Gerais, Brasil

\section{COMISSÃO EDITORIAL}

Adriana Braga I Pontifícia Universidade Católica do Rio de Janeiro, Brasil Felipe Costa Trotta I Universidade Federal de Pernambuco, Brasil CONSULTORES AD HOC

Édison Gastaldo I Universidade Federal Rural do Rio de Janeiro, Brasil Gisela Grangeiro da Silva Castro, Escola Superior de Propaganda e Marketing, Brasil Helio Kuramoto, Instituto Brasileiro de Informação em Ciência e Tecnologia, Brasil Juliano Maurício de Carvalho, Universidade Estadual Paulista, Brasil Maria Helena Weber, Universidade Federal do Rio Grande do Sul, Brasi Paulo Carneiro da Cunha Filho, Universidade Federal de Pernambuco, Brasil Vera Regina Veiga França, Universidade Federal de Minas Gerais, Brasil EDIÇÃO DE TEXTO E RESUMOS I Susane Barros SECRETÁRIA EXECUTIVA I Juliana Depiné EDITORAÇÃo ELETRÔNICA I Roka Estúdio
COMPóS I www.compos.org.br

Associação Nacional dos Programas de Pós-Graduação em Comunicação

Presidente

Itania Maria Mota Gomes

Universidade Federal da Bahia, Brasil

itania@ufba.br

Vice-presidente

Julio Pinto

Pontifícia Universidade Católica de Minas Gerais, Brasil juliopinto@pucminas.br

Secretária-Geral

Ana Carolina Escosteguy

Pontifícia Universidade Católica do Rio Grande do Sul, Brasil carolad@pucrs.br 